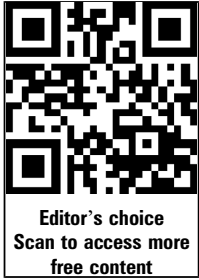

'Department of Philosophy, Queens University, Ontario, Canada

${ }^{2} \mathrm{AMC}$, University of Amsterdam, Amsterdam, The Netherlands

Correspondence to Dr Udo Schuklenk, Department of Philosophy, Queens University, Watson Hall, Kingston, Ontario K7L 3N6, Canada;

udo.schuklenk@gmail.com

Received 29 August 2014 Revised 13 March 2015 Accepted 2 April 2015 Published Online First 2 May 2015

\section{Linked}

- http://dx.doi.org/10.1136/ medethics-2014-102150

- http://dx.doi.org/10.1136/ medethics-2015-102810

- http://dx.doi.org/10.1136/ medethics-2015-102811

- http://dx.doi.org/10.1136/ medethics-2015-102812

- http://dx.doi.org/10.1136/ medethics-2015-102814

- http://dx.doi.org/10.1136/

medethics-2015-102966

\section{CrossMark}

To cite: Schuklenk U, Van de Vathorst S. J Med Ethics 2015:41:577-583.

\title{
Treatment-resistant major depressive disorder and assisted dying
}

\author{
Udo Schuklenk, ${ }^{1}$ Suzanne van de Vathorst ${ }^{2}$
}

\begin{abstract}
Competent patients suffering from treatment-resistant depressive disorder should be treated no different in the context of assisted dying to other patients suffering from chronic conditions that render their lives permanently not worth living to them. Jurisdictions that are considering, or that have, decriminalised assisted dying are discriminating unfairly against patients suffering from treatment-resistant depression if they exclude such patients from the class of citizens entitled to receive assistance in dying
\end{abstract}

\section{INTRODUCTION}

Opinion polls suggest that many of those who support the decriminalisation of assisted dying wish to limit the availability of assisted dying to competent adults suffering from an incurable physical illness that is affecting their quality of life to such an extent that they consider their continuing existence undesirable. ${ }^{1}$ This is not terribly surprising. The case for making assisted dying available to adults meeting those criteria is probably the easiest to understand. Respecting and supporting the voluntary self-regarding end-of-life choices made by such suffering competent adults is not a particularly controversial stance among the citizenry of many liberal Western democracies. The value of selfdetermination rightly holds significant sway in the global north.

We argue in this paper that limiting access to assisted dying to people with incurable physical illnesses unjustly discriminates against competent people who struggle with psychiatric illnesses that render their lives not worth living to them and that motivate them to request assistance in dying.

A case in point is people suffering from treatment-resistant major depressive disorder. The opinion surveys alluded to earlier indicate that the majority of Canadians and also of the Dutch are currently opposed to making assisted dying available to clinically depressed people. This is implied in survey results showing overwhelming societal support for the decriminalisation of assisted dying only for terminally ill patients, but also in at least one small-scale survey from the Canadian city of Edmonton. Seventy-five per cent of 356 people surveyed thought that assisted dying ought not to be made available to patients with treatment-resistant depression (TRD). ${ }^{2}$ Similar results can be found in surveys of the Dutch general public. When presented with the case of a middle-aged woman suffering from recurrent, TRD, $28 \%$ of the Dutch general public agreed that euthanasia would be justified in her case, $52 \%$ disagreed and 20\% were uncertain. It is remarkable that approximately $35 \%$ of those surveyed stated that in their opinion 'severe depression' does not constitute unbearable suffering. This compares unfavourably to public opinion on metastatic cancer. Here $65 \%$ of survey respondents thought euthanasia is justified in that case, $15 \%$ disagreed and 19\% were uncertain. The same case vignettes presented to doctors and nurses yielded different results. Fifty-one per cent of the doctors and $58 \%$ of the nurses labelled TRD as 'unbearable'. And 35\% of doctors and 36\% of nurses thought that euthanasia was justified in a case like this. ${ }^{3}$ A spokesperson for a UK antichoice activist group (Care Not Killing) underlines the attitudinal issues likely expressed in these survey results, when he refers to "those people who are not terminally ill and are probably just (sic!) suffering from clinical depression". ${ }^{4}$ An influential legislator, representing one of the governing coalition parties in the German government, mentioned in a recent interview that he is hopeful of achieving majority support in the federal parliament for the introduction of assisted suicide legislation. He hastened to add that depression would render a patient ineligible for assisted suicide. ${ }^{5}$ The devastating suffering caused by major clinical depression clearly is not given the same weight as comparable suffering caused by a physical (somatic) illness.

Those who support acceding to assisted dying requests made by competent adults (and possibly mature minors) for irreversible conditions that render a patient's life permanently not worth living to them have good reason to support the availability of assisted dying for competent patients suffering from TRD or other psychiatric disease.

The case for respecting self-regarding actions resulting from autonomous choices, particularly at unquestionably crucial junctures in our lives, has been made by philosophers of various philosophical traditions, covering thinkers ranging from John Locke to John Stuart Mill to Immanuel Kant. There is no need for us to rehearse here their well-known arguments. It is unnecessary to establish this case in this particular paper because our argument is directed at those who already support the availability of assisted dying for competent patients suffering from catastrophic illness. The case for why specifically in end-of-life decisionmaking we should enable willing and well-trained professionals to assist those requesting assisted dying has also been made by many secular philosophers. ${ }^{6}$ These arguments constitute well-trod ground in bioethics. ${ }^{2}$ 
Incurable disease conditions that are not terminal by most definitions can also render competent people's lives not worth living in their own well-considered judgement. For these and other reasons, a Canadian expert panel in their report on end-of-life decision-making in that country recommended that terminal illness not be made a necessary condition for access to assisted dying. The panellists wrote, "the Panel recommends against using 'terminal illness' as a prerequisite for requesting assistance. [...] There is no precise science to providing a prognosis of a terminal illness in terms of a specific length of time. Healthcare providers cannot be accurate enough, and if the statute or policy does not include a time restriction then the condition 'terminal illness' becomes too broad. [...] If the term 'terminal illness' is made a necessary condition in the statute, then it would be under-inclusive; there are many individuals whose lives, to them, are no longer worth living, who have not been diagnosed with a terminal illness. They may be suffering greatly and permanently, but are not imminently dying. There is no principled basis for excluding them from assisted suicide or voluntary euthanasia." ${ }^{2}$

We argue in this paper that jurisdictions considering the decriminalisation of assisted dying would be well-advised not to exclude competent patients suffering from debilitating, incurable, but not terminal conditions, somatic or psychiatric, from this end-of-life option. While public support for the availability of assisted dying for terminally ill patients is at an all time high in various Western countries, there is actually no 'terminally ill' clinical diagnosis. What supporters of this threshold criterion probably have in mind is a catastrophic illness that will foreseeably and in the reasonably near future kill the person requesting assistance in dying. They empathise with the end-of-life choices a dying patient with late-stage cancer might make, and they think we ought to respect such difficult decisions even to the point of providing assisted dying.

Of course, there are some possibly relevant differences between major depression and terminal cancer. What makes TRD and other chronic conditions obviously different are the time horizons. A patient suffering from treatment-resistant major depressive disorder can live-however miserably-to old age. An ethical question is whether we should, as a society that permits assisted dying, provide access to such a service to these kinds of patients, too. Unlike with the dying patient with cancer, there is at least a chance that a successful treatment for what is currently described as treatment-resistant major depressive disorder might be developed over a patient's lifetime.

Another issue that arguably makes this scenario, in ethically important ways, different from, say, dying patients with latestage cancer is the difficulty encountered by psychiatrists when it comes to diagnosing a patient as suffering from TRD disorder. A misdiagnosed patient might ask for assisted dying and receive the requested service when competent psychiatric, psychotherapeutic or other clinical care might have permitted her to improve her quality of life to such an extent that she would not have wanted to see her life prematurely terminated. If there are demonstrable difficulties in arriving at a reliable prognosis, there could be problems with predicting reliably future outcomes.

We will now provide a brief summary of relevant information about (treatment-resistant) depression as well as offer salient patient accounts of their experiences.

\section{BACKGROUND TRD}

How significant a problem is depression in the first place? A recent survey article in Nature concludes that in terms of years lost to disability depression accounts for the biggest share of the world's burden of disease. Major depressive disorder and bipolar mood disorder are reportedly the main drivers underlying about $60 \%$ of the estimated 800000 annual suicides globally. ${ }^{7}$

The literature on TRD is confusing since the term may be used to describe "no response to at least one treatment" ${ }^{8}$ or 'no response to all reasonably available treatments'. However, it has been suggested that roughly $20-33 \%$ of all people suffering from clinical depression suffer from a treatment-resistant variety. ${ }^{10}$ Olchanski and colleagues propose this definition: "Treatment-resistant depression (TRD) is generally defined as failure to achieve remissions despite adequate treatment." ${ }^{11}$ Today the term is usually used to describe patients suffering from major depressive disorder who are essentially unresponsive to conventional therapeutic efforts. ${ }^{12}$ Some authors have flagged doubts about the efficacy of antidepressants and the studies that led to their approval by regulatory agencies. ${ }^{13}$ We do not wish to debate the plausibility of their analyses, except to note that in the peer-reviewed literature statements such as this are not uncommon: "Despite the pervasive belief regarding the effectiveness of antidepressants and cognitive therapy among physicians and society at large [the largest antidepressant trial ever conducted showed that]... antidepressants and cognitive therapy fail to result in sustained positive effects for the majority of people who receive them." ${ }^{14}$ Similarly, cognitive bias modification interventions are popular treatment modalities for patients suffering from depression and anxiety disorder. A recent meta-analysis of the efficacy of such interventions concludes: "CBM may have small effects on mental health problems, but it is also very well possible that there are no significant clinically relevant effects." ${ }^{15}$ One study has followed 118 patients with TRD in a specialist tertiary care facility for a period of between 8 and 84 months, with a view to establishing what the long-term prospects of those patients are. About $40 \%$ of these patients, despite state-of-the-art specialist care, experienced persistent subsyndromal depression or persistent depressive episodes. ${ }^{8}$

Whatever the rights and wrongs of standard therapies deployed to treat patients suffering from depression, what is evident is that they fail a substantial portion of patients who have been trying these treatments over extended periods of time. What also matters to our argument, and what follows from the described treatment failure, is that a significant number of patients suffering from treatment-resistant major depressive disorder have 'little hope of recovering from their debilitating disease'. ${ }^{16}$ Perhaps counterintuitively this strengthens their case in favour of access to assisted dying rather than weakens it. The fact that they are not afflicted with an illness that will end their lives in the short term means that they do not have a 'natural way' out of their continuing suffering. A patient with late-stage cancer who is denied euthanasia may die not the death she requested, but her suffering will end soon. The same cannot be said of a person suffering treatment-resistant major depressive disorder.

It is difficult to make the suffering experienced by clinically depressed people intersubjective. That is undoubtedly one of the reasons why the general public is less sympathetic to such patients requesting assistance in dying compared with patients with late-stage cancer. In the minds of many, empathy with a clinically depressed person is not different to our empathy with someone who just feels a bit bad. We are addressing this issue by providing here excerpts from first-person accounts given by patients suffering from clinical depression, describing what it feels like and what it means to them to suffer from this ailment. A patient writes: 
You don't feel hopeful or happy about anything in your life. You're crying a lot for no apparent reason, either at nothing, or something that normally would be insignificant. You feel like you're moving (and thinking) in slow motion. Getting up in the morning requires a lot of effort. Carrying on a normal conversation is a struggle. You can't seem to express yourself. You're having trouble making simple decisions. Your friends and family really irritate you. You're not sure if you still love your spouse/significant other. Smiling feels stiff and awkward. It's like your smiling muscles are frozen. It seems like there's a glass wall between you and the rest of the world. You're forgetful, and it's very difficult to concentrate on anything. You're anxious and worried a lot. Everything seems hopeless. You feel like you can't do anything right. You have recurring thoughts of death and/or suicidal impulses. Suicide seems like a welcome relief. Even on sunny days, it seems cloudy and gray. You feel as though you're drowning or suffocating. Your senses seem dulled; food tastes bland and uninteresting, music doesn't seem to affect you, you don't bother smelling flowers anymore. ${ }^{17}$

This excerpt gives a vivid idea of what it means for an individual to suffer from depression. Imagine what suffering from TRD must be like, knowing that this state will never end.

A psychiatrist tried to explain depression to readers of the New York Times-lamenting the impossibly ambitious nature of the effort. She writes,

Suicidal depression involves a kind of pain and hopelessness that is impossible to describe- and I have tried. I teach in psychiatry and have written about my bipolar illness, but words struggle to do justice to it. How can you say what it feels like to go from being someone who loves life to wishing only to die?

Suicidal depression is a state of cold, agitated horror and relentless despair. The things that you most love in life leach away. Everything is an effort, all day and throughout the night. There is no hope, no point, no nothing.

The burden you know yourself to be to others is intolerable. So, too, is the agitation from the mania that may simmer within a depression. There is no way out and an endless road ahead. When someone is in this state, suicide can seem a bad choice but the only one. ${ }^{18}$

The Netherlands and Belgium are unusual among countries that permit assisted dying insofar as clinically depressed people are-in principle-eligible for assisted dying, provided the above-mentioned conditions of due care are met. We will briefly review some of the evidence as far as the use of this option by patients suffering from clinical depression is concerned.

\section{DEPRESSION AND ASSISTED DYING IN THE NETHERLANDS}

In the Netherlands, euthanasia and assisted suicide ${ }^{19}$ are available to people with TRD, provided they meet the following conditions (due care criteria): ${ }^{20}$

- their requests are explicit, voluntary and well-considered;

- they are aware of their condition and prospects;

- their suffering is unbearable and there is no prospect of improvement based on the state of the medical science at the time when the decision is made;

- there are no reasonable alternatives to alleviate the suffering;

- an independent physician has given her written opinion on these issues;

- a doctor has provided assisted dying in a professional manner (she exercises due medical care and attention).

It is worth noting from the outset that assisted dying is an option only made available to very few patients suffering from clinical depression. 2013 saw an increase in cases of euthanasia for patients with psychiatric illnesses. A total of 42 cases were reported-as is legally required-to the Dutch Euthanasia Review Committee. The 42 cases reported in 2013 compare against 12 in 2012. Of these 42 cases, 32 were investigated by the Committee in 2013 and the findings published. In 22 of these 32 cases, depression was mentioned as (one of the) the cause(s) of suffering. Next to depression many of these patients also suffered from anxiety disorder, phobias, personality disorder or memory loss (a known side effect of repeated ECT-therapy). One patient was between 30 and 40 years of age, two between 40 and 50, two between 50 and 60, five between 60 and 70, three between 70 and 80 and four between 80 and 90. For some the loss of a partner or the incidence of another disease turned out to be the last straw, others were just exhausted from battling a therapy-resistant disease. All 32 cases were judged to comply with the Dutch Euthanasia Law, implying that the due care criteria were met. The reviewed cases are all published on the Committee's website. ${ }^{21}$

Is this increase in the number of reported case a sign of a slippery slope or merely a sign of a treatment option, a service, requested more frequently? The reported increase is probably mostly due to the start of the 'end-of-life' clinic, an organisation that aims to grant euthanasia to all who fulfil the due care criteria in the Netherlands but who have been unable to obtain assisted dying from their physician. The start of this service in March 2012 led to a significant number of applications from patients who were determined to end their life by means of assisted dying, among them were a large number of patients with psychiatric illnesses (38\% of applicants). Some $62 \%$ of these patients with psychiatric illnesses were refused euthanasia mostly because their death wish was judged to be more or less impulsive, and therefore did not meet the due care criteria. ${ }^{22}$ The Dutch Minister of Justice revealed in August 2014 in a letter to the Dutch Parliament that there were no signs of a further increase in $2014 .^{23}$ The reported increase is also partly due to psychiatrists' increasing recognition of the suffering endured by such patients. The Dutch Psychiatric Society first published a guideline on euthanasia for patients with psychiatric illnesses in 1998. This guidance was revised in 2004 and again in 2009. It has led to more debate and also to better knowledge of the due care criteria among psychiatrists. An important condition in these guidelines is that for patients with a psychiatric disease a second psychiatric assessment is necessary. This serves to ensure that these patients with psychiatric illnesses are indeed competent, and it is also designed to ensure that no therapeutic options are overlooked. Patients with psychiatric illnesses will thus be evaluated not by two independent physicians, as is the case with all other patients requesting assisted dying, but by three independent physicians, two of whom are psychiatrists.

In the review process of cases of people suffering from depression who were granted assistance in dying in the Netherlands, the competence question is seldom a matter of discussion or controversy. Legally, competence is understood as 'being able to review and decide about the case at hand'. Patients need to demonstrate a reasonable understanding of what it is that they request, they need to provide a persuasive justification for their request and they have to persuade three doctors independent of each other of this. Suffering from a psychiatric disease such as a depression does not automatically preclude patients from being aware of what they are experiencing and of what their future prospects are. ${ }^{24}$ An exception to this affects typically psychotic depression because treatment decisions by such patients are often 'not arrived at competently and should be overridden/ignored'. 25 
The situation in Belgium, where assisted dying is available to patients experiencing 'unbearable mental suffering due to an irreversible disease', is not dissimilar to what is happening in the Netherlands. In 2011, this motive was the only reason provided in $3.5 \%$ of all registered euthanasia cases- $n$ being $1133 .^{26}$ Deschepper et $a l^{27}$ report that "of 100 euthanasia requests based on mental suffering received in Belgium between 2007 and 2011 and followed up until February 2013, 33 were granted, but another five were not and ended in the patient committing suicide".

\section{TRD, COMPETENCE AND AUTHENTICITY}

Typically people ask for assistance in dying for an amalgam of reasons that are not exclusively tied to pain and pain-related suffering. Concerns about loss of control over one's life, the absence of a meaningful future, the pointlessness of getting through the day, as well as concerns about becoming a burden on one's family feature, were among reasons given by people asking for assisted dying. Requests for assisted dying "arise from a complex combination of physical, psychosocial, and existential suffering-importantly, this is a type of suffering that has objective as well as subjective elements". ${ }^{2}$ Dees and colleagues note in their meta-analysis of 35 empirical studies on suffering, "a closer look at the patients' motivations ... showed that patients express their unbearable and unrelieved suffering in terms of pain, weakness, functional impairment, dependency, being a burden, hopelessness, indignity, intellectual deterioration, perception of loss of oneself, loss of autonomy, and being tired of life". ${ }^{28}$

Existing surveys such as those mentioned in our introduction suggest that the public supports assisted dying primarily, if not exclusively, in cases of terminal illness. This does not map well on the actual reasons people provide-on reflection-about the kinds of circumstances under which they would consider asking for assisted dying. In the Netherlands, for instance, many of the reasons given for (granted) requests include concerns not directly linked to a physical ailment. They include, 'mental symptoms', 'loss of dignity' and other psychological states of mind. ${ }^{29}$ Keeping this in mind, let us return to the issue of TRD and assisted death.

Patients diagnosed as suffering from treatment-resistant major depression would have undergone extensive long-term professional psychiatric care. Typically they would have tried a fairly significant number of antidepressants, psychotherapy, probably electroconvulsive therapy, and they would have experienced the failure of these varied therapeutic approaches. In the Netherlands, for instance, the Dutch Association of Psychiatrists considers a patient as treatment-resistant, "if the following interventions have been proven ineffective: all applicable regular biological treatments; all applicable psychotherapeutic treatments; social interventions which can make the suffering more bearable". 9

It is often claimed that these patients' judgements about their individually experienced quality of life should not be taken at face value because it is the depression that causes their suffering as well as clouds their judgements of their lives. Antieuthanasia campaigner John Keown, for instance, refers to their requests as being 'warped by clinical depression'. 30

Evidently, depression significantly influences, possibly even determines, an individual's view of her reality. It also dramatically impacts on the quality of life lived in that reality. There have been suggestions that depressed patients' evaluation of their lives' prospects-including future improvements-are influenced by their depression. This is undoubtedly correct, but it does not address the competence question. A great deal of research effort went into evaluating the question of whether "depressed people are not merely more negative than people who are not depressed, but [whether] they are inaccurate in their negative views". It turns out that "testing this claim has proven difficult. A definitive body of empirical work has yet to emerge in this area, despite substantial efforts by several research groups". ${ }^{31}$ In other words, despite substantial research efforts it was not possible to demonstrate that depressed people's evaluations of their quality of life and of their future life prospects are necessarily incompetent. In our view, it is simply a question of procedural justice to treat competence assessments affecting patients suffering from depression no different to competence assessments affecting other groups of patients. To date, there is no evidence that depression per se renders patients incompetent.

However, despite the absence of evidence demonstrating patient incompetence, the soundness of these patients' quality-of-life judgements and of their evaluation of future prospects is questioned regardless. After all, how could they not want to live a long life, just as-all other things being equalmost of us want to do who do not suffer from depression. The problem with this line of reasoning is that these patients might well have wanted to live long were it not for their inability to regain a quality of life that would have made their continuing existence worthwhile to them.

In many cases of successfully thwarted suicide attempts, the rescued is grateful that their suicide attempt was successfully subverted. In fact, this provides the moral, and often the legal, justification for interfering with the self-regarding choices and the bodies of people who undertake suicide attempts. We assume that they would regret their attempt once they recover. This analysis makes a good deal of sense with regard to suicide survivors who consider their continuing lives worth living when they are asked how they think about their failed, subverted suicide attempt. The same response is unlikely forthcoming in case of patients who find themselves in circumstances such as those characterised by TRD. They will continue to see their lives as not worth living for the reasons outlined. We mentioned, already, that in Belgium a fair number of patients who request euthanasia based on mental suffering, and whose requests are denied, commit suicide eventually. A systematic review of suicide prevention strategies notes that "many depressed patients who survive a suicide attempt will make further suicide attempts [...]". ${ }^{32}$ The study authors see this as indicative of the need for further interventions. The problem with such an approach is that at least some of these patients may have made a reasonable choice when they tried to end their lives and this is what motivates their repeat attempts. After all, they have been at the receiving end of futile therapeutic interventions from a profession that-to many such patients-is not dissimilar to the naked emperor when it comes to their particular ailment.

To what extent are the views patients suffering from depression express a reflection of their authentic selves? Do their views indicate an interpretation of their experienced life reality that appears irrational? We should be careful here not to exclude by definition depression as a constitutive part of her authentic self. A TRD person's authentic self is by necessity defined to a significant extent by her illness. That does not render her expressions of her views any less authentic or less plausible. Nor does it render them unrealistic. A prolonged TRD creates a depressing reality by any stretch of the imagination. It is not just that life is meaningless to many of these patients, that it has no flavour, it is also the case that there is no 
realistic hope that this grey veil will lift. People with TRD are not 'just depressed' in a colloquial sense. As we have seen earlier, they experience no joy in life, and have not for a long time, and they are right to think that this will not change, based on everything that is known at the time of their decision-making.

Even if it was the case that there existed a to-be-rediscovered authentic self that is distinct from the self influenced by depression, it is not clear that an argument from authenticity against assisted dying could then succeed. This line of reasoning could only work if there was a realistic chance for a person with TRD to recover her pre-depression authentic self. This does not appear to be the case, based on our current understanding of what treatment-resistant major depressive disorder is. ${ }^{33}$

A patient's depressed self to a large extent constitutes her authentic evolved self. That does not mean that TRD is not appropriately described at least to some extent by a loss of individual integrity and a loss of a (healthier) self. It is true that the person these patients once were, and that they likely long to be, they are no longer and they will not be again. ${ }^{34}$ However, none of this renders them per se incompetent or gives us reason to disregard their considered choices. None of this demonstrates an impaired assessment of where they are in their lives and where they would be in their lives should they continue to live.

We will now turn to what we consider the most serious objections to our analysis.

\section{ARGUMENTS AGAINST MAKING ASSISTED DYING AVAILABLE TO PEOPLE WITH TRD}

\section{Successful treatments might be developed}

One could object that a chronic condition is different to a terminal condition that kills a patient in the foreseeable future insofar as there is always a chance that a successful treatment will come about that will result in successful remission of the ailment in question. This is, of course, always a possibility. However, if the pace of developments leading to therapeutic success in major depressive disorder is anything to go by, many people suffering from TRD would have reason to be sceptical about the odds of such a treatment regimen coming about within a timeframe that they would consider acceptable. Our view would be that those patients who meet the due care criteria we outlined earlier are perfectly entitled to evaluate the likelihood of successful treatment becoming available and making end-of-life choices based on their evaluation of the state of the medical evidence that exists at the time when they wish to make their choices. It seems unreasonable for us to deny them this choice based on a hunch that a successful treatment might come around soon, or that they might experience a spontaneous, unexplained remission of symptoms.

A second point is worth considering with regard to the potential future treatment argument. Denying patients who meet the due care criteria the right to make this end-of-life choice, in the hope of preserving their lives until a successful treatment is developed, ignores unjustifiably the high burden that is paid by patients who happen to wait unsuccessfully for a successful treatment that may not come about at all or that may come about too late for many patients to enjoy its fruits. This argument seems to assume without further justification that refusing treatment-resistant patients with major depressive disorder access to assisted dying is cost-neutral or that the cost is sufficiently minor that it ought to be borne by the patients in question. Our view would be that this is exactly an evaluation that competent patients ought to be permitted to make based on their life reality. It seems beyond reasonable doubt to us that many of those who repeatedly try to commit suicide do not consider the lack of access to assisted dying to be cost-neutral to them. They evidently consider their continuing existence such an overwhelming burden to themselves that they undertake these suicide attempts in the first place.

\section{Psychiatrists are unable to diagnose TRD with a sufficiently} high level of certainty

Another argument against the availability of assisted dying for patients with treatment-resistant major depressive disorder is that psychiatry at the best of times is an imprecise science. Depressed people who do not suffer from treatment-resistant major depressive disorder might mistakenly be diagnosed as such and provided with assistance in dying when better clinical care might have permitted them to live their lives in ways that they would have considered worth living.

We think that even if it were true that modern psychiatry is unable to diagnose major depressive disorder to a degree that is comparable to diagnostic reliability in other medical specialties, patients would still have to live with the consequences of those failures. In our case, they would have undergone many years of failed therapeutic efforts involving various specialist professionals. If after all those years they find themselves in circumstances where they do not consider the burdens of their disease condition on their quality of life acceptable, we ought to respect decisions they make based on their actual life reality.

This should not stop us from aiming to improve the quality of care provided, but patients should not reasonably be expected to continue lives they do not consider worth living while psychiatry treatments' nirvana remains elusive.

\section{We should invest in the provision of better levels of professional care rather than in making assisted dying available}

Variations of this argument will be familiar to readers aware of ethical and policy debates on assisted dying. The concern is, essentially, that we have our priorities wrong. Instead of focusing on improving the quality of life of depressed people, we facilitate their untimely demise. Similar arguments are often made by opponents of assisted dying generally. They charge that if we focused on improving the provision of palliative care requests for assisted dying would become so negligibly small that changes in policy on the matter would not be justifiable. There are two replies to this: one is that we know that even with the best quality palliative care there would always remain a substantial enough number of patients who would benefit from the availability of assisted dying to make policy changes desirable and ethically defensible. Absent significant risks it is unclear why these patients should then be denied access to assisted dying. Another possible response is that patients continue to live not in the best of all possible worlds, but in a suboptimal world. We have no right to require of them to continue living while we try to bring our current suboptimal situation closer to what would be an optimal situation. The availability of assisted dying for treatment-resistant depressive disorder does not conflict with the need to improve the professional care that patients suffering from major depressive disorder receive. We can and we should do both.

\section{Offering assisted dying to people with TRD reinforces loss of hope}

Berghmans and colleagues discuss the argument that "offering physician assisted suicide [to refractory mentally ill people] reinforces loss of hope and demoralization" in mentally ill people in their paper. The authors concede that in some patients what 
they call 'demoralisation syndrome' could take away these patients' capacity to make an autonomous choice. However, they insist that that is not always or necessarily the case. Berghmans and colleagues note that "it is uncontested that fostering hope in patients suffering from mental illness is an important ingredient of mental health care. In some cases, however, hope reaches its limits and may become illusory. This is the case when all reasonable treatment options are tried, exhausted and have proven unsatisfactory". ${ }^{35}$ They conclude that offering assisted dying to mentally ill patients who meet the due care criteria "does not necessarily imply taking away hope and can in exceptional circumstances be ethically acceptable". 35, p.437

\section{EXAMPLES OF RECENT ASSISTED DYING LEGISLATIVE EFFORTS FAILING PATIENTS WITH TRD}

We are concerned about scope when it comes to the criteria that guide access to assisted dying in jurisdictions that consider decriminalising assisted dying in some form or shape. At the time of writing, a number of legislative proposals were being debated in North America and in Europe. Each of them would prevent the kinds of patients we have written about in this paper from accessing assisted dying.

In Canada's French-speaking province of Quebec, legislators recently passed Bill 52. This legislation is designed to make assisted dying legally available in the province. Quebec's is the first legislature in North America that introduces assisted dying legislation that would include a voluntary euthanasia option, in addition to assisted suicide. Earlier drafts of the bill did not include a provision requiring that patients are near the ends of their lives, but the version that was eventually passed in the National Assembly included an access threshold requiring that patients 'be at the end of life'. ${ }^{36}$ However, a judgement by the Supreme Court of Canada would appear to open the door for some competent patients with TRD to avail themselves of assisted dying. It stipulates the following threshold conditions for access to assisted dying: "(1) the person affected clearly consents to the termination of life; and (2) the person has a grievous and irremediable medical condition (including an illness, disease or disability) that causes enduring suffering that is intolerable to the individual in the circumstances of his or her condition." ${ }^{37}$

A group of eminent German bioethicists launched a legislative proposal aimed at making assisted suicide legally available in Germany. Their document aims to provide a justification for making assisted suicide available only to people suffering from a terminal illness with very limited life expectancy, quite similar to Quebec's legislation. The authors specifically stress their intention to prevent patients with psychiatric illnesses (of any kind) from accessing assisted suicide. ${ }^{38}$

At the time of writing, the UK's House of Lords was debating an assisted dying bill. It would limit access to assisted dying to 'terminally ill' patients expected to die within 6 months of their request. ${ }^{39}$ Like the German proposal, it aims to make assisted dying only available to people suffering from particular illnesses that will result in their deaths in the near future.

These legislative proposals are ill-advised. They are unjust insofar as they ignore the continuing severe suffering of some chronically ill, competent people who happen to be not at the end of their biological lifespans.

\section{RECOMMENDATIONS}

We recommend that jurisdictions considering the decriminalisation of assisted dying do not limit access to such services to patients suffering from a however defined terminal illness.
Relevant eligibility criteria should include competence and a patient's illness-caused inability to live a life he or she considers worth living.

Patients with TRD suffer in ways that may be hard to comprehend by those of healthy mind, but that should not prevent us from recognising their suffering, and it should not prevent us from making assisted dying available to this group. Medical ethicists should discuss these issues with medical students and doctors. Ongoing discussions will help us evolve our considered views on this matter.

The following are defensible criteria that could guide those considering to regulate assisted suicide:

- The patients are competent to evaluate their current situation.

- The patients are competent to evaluate their future prospects based on the scientific evidence available at the point in time when they request assistance in dying.

- The patients' decision is voluntary and informed.

- The patients' quality of life is such that they do not consider it worth living, and the likelihood of improvement is exceedingly small or non-existent.

- The patients repeat their requests over a reasonable period of time.

\section{Twitter Follow Udo Schuklenk @schuklenk.}

Acknowledgements The authors thank the anonymous reviewers of a previous version of this paper as well as audiences at Western University and Queens University where earlier drafts of this manuscript were read for critical comments. Thanks also to Gerty Casteelen, Sandra Martin, Anna Pacholczyk, Agatha Sagan, Peter Singer and Urban Wiesing for helpful further references and critical comments. Dominic Wilkinson of this journal helped in improving this manuscript in numerous ways.

Contributors Both authors contributed to the conception, writing and editing of the manuscript.

Competing interests None declared.

Provenance and peer review Not commissioned; externally peer reviewed.

\section{REFERENCES}

1 Schuklenk U, van Delden JJM, Downie J, et al. End-of-life decision-making in Canada: the report by the Royal Society of Canada Expert Panel on end-of-life decision-making. Bioethics 2011;25(Suppl 1):1-73, at 18.

2 Schuklenk U, et al. 2011. Op.cit. 18.

3 Van Delden JMM, Van Der Heide A, Van De Vathorst S, et al. Kennis en opvattingen van publiek en professionals over medische bes/uitvorming en behandeling rond het einde van het leven-Het KOPPEL-onderzoek. The Hague: ZonMW, 2011.

4 Siddique $\mathrm{H}$. One in five visitors to Swiss assisted-dying clinic from Britain. the Guardian August 21, 2014. http://www.theguardian.com/society/2014/aug/20/ one-in-five-visitors-swiss-suicide-clinics-britain-uk-germany (accessed 21 Aug 2014).

5 Anonymous. Sterbehilfe: Lauterbach will Aerzten Beihilfe zum Suizid erlauben. Der Spiege/ 24 August 2014. http://www.spiegel.de/politik/deutschland/ sterbehilfe-karl-lauterbach-will-aerzten-beihilfe-zum-suizid-erlauben-a-987718.html (accessed 24 Aug 2014).

6 Dworkin R, Nagel T, Nozick R, et al. Assisted suicide: the philosophers' brief. The New York Review of Books 27 March 1997. http://www.nybooks.com/articles/ archives/1997/mar/27/assisted-suicide-the-philosophers-brief/ (accessed 24 Aug 2014).

7 WHO. Suicide Prevention. N.d.: Geneva. http://www.who.int/mental_health/ prevention/suicide/suicideprevent/en/ (accessed 24 Aug 2014).

8 Fekadu A, Rane LJ, Wooderson SC, et al. Prediction of longer-term outcome of treatment-resistant depression in tertiary care. Br J Psychiatry 2012;201:369-75.

9 Berghmans R, Widdershoven G, Widdershoven-Heerding I. Physician-assisted suicide in psychiatry and loss of hope. Int J Law Psychiatry 2013;36:436-43, on 440.

10 Souery D, Papakostas Gl, Trivedi MH. Treatment-resistant depression. J Clin Psychiatry 2006:67(s6):16-22.

11 Olchanski N, Mclnnis Myers $M$, Halseth $M$, et al. The economic burden of treatment resistant depression. Clin Ther 2013;35:512-22.

12 Souery D, et al. 2006. Op.cit. p. 17.

13 loannidis JPA. 2008. Effectiveness of antidepressants: an evidence myth constructed from a thousand randomized trials? Philos Ethics Humanit Med 3:14. http://www. peh-med.com/content/3/1/14/abstract (accessed 5 Jan 2015). 
14 Pigott HE, Leventhal AM, Alter GS, et al. Efficacy and effectiveness of antidepressants: current status of research. Psychother Psychosom 2010;79:267-79.

15 Cristea IA, Kok RN, Cuijpers P. Review article: efficacy of cognitive bias modification interventions in anxiety and depression: meta-analysis. $\mathrm{Br} J$ Psychiatry 2015;206:7-16.

16 Schlaepfer TE, Ågren H, Monteleone P, et al. The hidden third: improving outcome in treatment resistant depression. J Psychopharmacol 2012;26:587-602.

17 Gray DE. What does depression feel like? Wing of Madness Depression Guide 1 July 2013. http://www.wingofmadness.com/what-does-depression-feel-like/ (accessed 10 Jul 2014).

18 Redfield Jamieson K. To Know Suicide. New York Times 16 August 2014: A19. http://www.nytimes.com/2014/08/16/opinion/depression-can-be-treated-but-it-takescompetence.html (accessed 12 Sep 2014).

19 The Dutch euthanasia act does not draw a distinction between euthanasia and assisted suicide.

20 http://www.euthanasiecommissie.nl//mages/qa-euthanasie-engels-2011_tcm5233857.pdf (accessed 10 Jan 2015)

21 http://www.euthanasiecommissie.nl/oordelen/oordelen2013vo/ (accessed 10 Jan 2015).

22 Stichting Levenseindekliniek. Annual report 2013 [in Dutch], The Hague, 2013.

23 http://www.rijksoverheid.nl/documenten-en-publicaties/kamerstukken/2014/08/20/ kamerbrief-reactie-op-rondetafelgesprek-over-euthanasie-en-psychiatrie.html (accessed 10 Jan 2015).

24 Appelbaum P. Assessment of patients' competence to consent to treatment. N Engl J Med 2007;357:1834-40.

25 Rudnick A. Depression and competence to refuse psychiatric treatment. J Med Ethics 2002;28:151-5.

26 Deschepper R, Distelmans W, Bilsen J. Requests for euthanasia/physician-assisted suicide on the basis of mental suffering - vulnerable patients or vulnerable physicians? JAMA Psychiatry 2014;71:617-18.

27 Deschepper $\mathrm{R}$, et al. Op. cit. 617.
28 Dees $\mathrm{M}$, Vermooij-Dassen $\mathrm{M}$, Dekkers $\mathrm{W}$, et al. Unbearable suffering of patients with a request for euthanasia or physician-assisted suicide: an integrative review. Psycho-Oncology 2010;19:339-52.

29 Van der Heide A, Legemate J, Onwuteaka-Philipsen B, et al. Tweede evaluatie: Wet toetsing levensbeëindiging op verzoek en hulp bij zelfdoding. The Hague: ZonMw: Table 8.5, 2012:186.

30 Keown J. Euthanasia, ethics and public policy: an argument against legalisation. Cambridge: Cambridge University Press, 2002:56.

31 Strunk DR, Lopez H, DeRubeis RJ. Depressive symptoms are associated with unrealistic negative predictions of future life events. Behav Res Ther 2006;44:861-82.

32 Mann JJ, Apter A, Bertolote J, et al. Suicide prevention strategies: a systematic review. JAMA 2005;294:2064-74. http://jama.jamanetwork.com/article.aspx? articleid=201761 (accessed 24 Aug 2014).

33 We thank Gerty Casteelen for flagging this issue to us.

34 Wissbek $H$. 'To thine own self be true': on the loss of integrity as a kind of suffering. Bioethics 2012;26:1-7.

35 Berghmans R, et al. 2013, op.cit. 442.

36 Quebec National Assembly. 2013. An act respecting end-of-life care. P. 10f. http:/l www2.publicationsduquebec.gouv.qc.ca/dynamicSearch/telecharge.php? type $=5 \&$ file=2014C2A.PDF (accessed 28 Jan 2015]. We thank Sandra Martin for bringing this link to our attention.

37 Carter v. Canada (Attorney General), 2015 SCC 5 http://scc-csc.lexum.com/scc-csc/ scc-csc/en/item/14637/index.do (accessed 10 Feb 2015).

38 Pressemitteilung. 2014. Selbstbestimmung im Sterben—Fürsorge zum Leben Ein Gesetzesvorschlag zur Regelung des assistierten Suizids. 26 August 2014.-See also by the authors of the legislative proposal: Borasio GD, Jox R, Taupitz J, et al. 2014. Selbstbestimmung im Sterben-Fürsorge zum Leben Ein Gesetzesvorschlag zur Regelung des assistierten Suizids. Stuttgart: Kohlhammer.

39 House of Lords, Bill 6. Assisted Dying Bill. http://www.publications.parliament.uk/pa/ bills/lbill/2014-2015/0006/15006.pdf (accessed 3 Dec 2014). 